\title{
Research on Eco-Compensation System in China
}

\author{
Zhiwei Xiong \\ School of intercultural Studies, Jiangxi Normal University \\ 99 Zi yang Street, Nanchang 330022, Jiangxi, China \\ Tel: 86-791-601-3946 E-mail: lightinair@163.com
}

Cheng Shao

Department of Business and trade, Jiangxi BlueSky University

Beijing East Street 1118, Nanchang 330029, Jiangxi, China

Tel: 86-138-0352-0270 E-mail: shaocheng1213@sina.com

Received: November 5, 2010 Accepted: November 25, 2010 doi:10.5539/jas.v3n2p255

\begin{abstract}
Lack of eco-compensation system is an important reason for ecological degradation in our country to solve the problem on conservation, the establishment of eco-compensation system and finalization of the relevant rules thereof must be undertaken.

The eco-compensation system in China covers three main parts: eco-functioning area, river basin catchments, and natural resources exploitation. Different part corresponds to different mechanism. To expedite the process, China should give priority to north western part of China and focus her effort mainly in the three aspects: to further finalize the governmental compensation mechanism; to push strongly the market mechanism and to strengthen the basic work.

Keywords: Eco-Compensation, Operational mechanism, Overall framework, Recommendation of policy

The fast development of the modern science and technology and economy brings the mankind the unprecedented and prosperous physical life and results in that resources are dried up and with the ecosystem is broken at the meantime. Our country is a developing country, facing the dual mission of economic development and environmental protection currently. It is the problem that we have to face that how to protect resources reasonably, find out a balance point between the environmental protection and the economic development, and make the coordination development of the society and the nature come true. The compensation system of water and soil maintenance emphasizes that the ecological protection should be given economic compensation, namely carrying on maintenance to the damaged ecological environment in order to recover its ecological function and value. The people who benefit compensate the people who be subjected to which accords with the principle of continual development. The thought of the compensation of water and soil maintenance is more and more recognized by people. But the legal provision concerning the compensation system of water and soil maintenance currently is just constituted in the individual legal article of implemented law separately of some environment laws and lacks of special maneuverability provision about compensated style, compensated object, compensated form and compensated standard etc. Therefore, it is necessary to integrate the thought of the compensation of water and soil maintenance with the environment law system, carry on different system designs to different ecological repair and provide the practice of the compensation of water and soil maintenance with dependable legal basis. beneficial loss in order to carry out the uneconomical exterior of the inner part turn.
\end{abstract}

\section{The Definition}

In recent years, in order to protect ecological construction and water resources, the water protection zones have adopted a series of measures to strengthen the protection of water resources, which include water and soil concentrative disposal project, forests project for conserving water, water and soil conservation project. A series of policies have made to restrict the third grade industry development of the protection zone of water resources. Water resource has been divided into water supplying districts and using districts in administrative level. Although national finance has invested the massive expenditure to each hydraulic project, the basin protection zone of water resource has become the benefit paying area due to the industry development limitation in policy 
level as well as lacking manpower and technology investment especially great fund investment. At present, due to the protection of basin zone of water resource merely depend on local finance, the basin water source area sustainable development problem can not been fundamentally solved, and the unreasonable administrative dividing of basin zone, causing the river valley headwaters sanctuary and the river valley downstream use the water area can't be placed in same level position, then aggravate the no synchronous phenomenon of the economic development between the basin protection zone of water resource and the downstream zone.

The concept of ecological compensation includes the broad and narrow understanding. Broad ecological compensation includes compensation for environmental pollution and ecological function of compensation. Narrow ecological compensation, while others refer to the ecological function or ecological value of the compensation, including for the protection and restoration of ecological environment and its functions and to pay the price, sacrifice areas, units and individuals for economic compensation; on the use of land for development, minerals, forests, grasslands, water, wildlife and other natural resources and damage the natural landscape and ecological functions, or result in the loss of ecological value of the units and individuals for financial compensation.

\subsection{The Purpose of Eco-compensation System}

This paper taking the east river headwaters sanctuary as example, through analyzing the actuality of paying out and biennial of upriver and downriver, combined the obstacles of compensating mechanism of ecosystem resources, promote the purpose of constructing the compensating mechanism of ecosystem resources based on the law level. In this paper, how to reasonably set down the scope as well as the format and related fees collection standards of compensating mechanism of ecosystem resources, and how to reasonably made the benefit party assume the invested fund which used as improving the ecosystem benefit of basin protection zone have been investigated so as to achieve the whole and sustainable development of economy and social in basin protection zone.

\subsection{The Necessity of Eco-compensation System}

In 21 st century the conception of sustainable development has struck root in people's the hearts. On the way to pursue the sustainable development of ecology, society and economy, sustainable use of natural resources s is the foundation and assurance of sustainable development. The sustainable use and protection of water re resources $\mathrm{s}$ is the core of implementing the strategy of sustainable development in China. Ecological compensation mechanism is the basic theoretical framework of achieving the sustainable development of society. Following the international success of practical experience, on the basis of redefining the conception of ecological compensation, the authors present the theoretical basis of ecological compensation mechanism on the angle of ecological capital, sustainable development, external character and public goods, analyze the characteristic of public pay, market trade, one-to-one transactions, eco-mark compensation modes, elucidate the guiding principles of ecological compensation and give the concept of ecological compensation expending. By analyzing the theoretical research and practical activity of ecological compensation at home and abroad, the authors point out that our country's ecological compensation has the problems of mechanism failure and incomplete implementation framework, give the effective ecological compensation mechanism improvement strategies based on our country's status quo and sustainable development by doing research on the ecological compensation foundation, policy drafting, mechanism implementation, inspecting and management.

China is a country with a vast territory and a large population but limited forest resources, which is mainly distributed in the economically less developed regions. Therefore, it is particularly important to address the issue to establish forest eco-compensation mechanism to overcome the problems of inequity between the people and promote the public incentive for forest management and conservation. The definition of eco-compensation is deeply discussed based on the literature review of national and international initiatives. According to summary and analysis of the empirical work of forest eco-compensation at international level, some significant inspirations are drawing this paper. Based on them, this paper focuses on the forest eco-compensation mechanism of China. Firstly, integrating with the actual situation of China, the paper puts forward the policy framework of eco-compensation, the institutional framework of eco-compensation should be established among the multi-departments with different temporal and spatial scales. Secondly the types and ranges of forest eco-compensation are, further, studied, that is three levels of forest eco-compensation such as micro-level, macro-level as well as media-level, and then the standards of eco-compensation are primarily estimated, which include the three factors, namely direct expense of plantation, opportunity test for forests protection and benefits of the ecosystem services. Finally the recommendation is created in terms of above research conclusions, which is provide the vital important references for government policy making in the forest eco-compensation domain.

Protection of the ecological environment is not confined to one side to be rehabilitate the natural environment, 
but more importantly is its protection of national ecological safety and security of supply of agricultural products is of great significance, and establish and improve the ecological environment of the compensation mechanism is to safeguard the functioning of this important cycle of chain important link.

\subsection{The Current Situation of China on the Issue of Eco-compensation System}

In recent years, the establishment of a sound ecological environment in the pace is increasing in the compensation mechanism. 2001-2004, the countries of the Central forest ecological benefit compensation fund an experimental basis. Since 2005, the central government formally established the forest ecological benefit compensation fund, marks the compensation mechanism of forest ecological benefits, and is formally established. Now it is accumulated more than 200 billion Yuan invested, will focus on seven million hectares of ecological forest into the scope of compensation. In 2006, the State authorities issued on the progressive establishment of mining environmental management and ecological restoration accountability mechanisms guidance to the mines to make the deployment of a pilot eco-environmental compensation. At the same time, the central government also adopted to improve the standards of environmental protection expenditures and transfer payments coefficient approach, increase of Qinghai Three Rivers, south-middle part of the natural forests, water areas and protected areas such as financial transfer payment.

\section{The Meaningful Practices of Eco-compensation}

\subsection{Payment for Watershed Environmental Services}

Payment for watershed environmental services, that is PWES----In the economic, social, political and legal conditions for preparation of the premise, while China's current environment with clear property rights and responsibilities, resources shortage, environmental degradation and uneven development between regions has become a very serious social and economic problems, impact of China's scientific development and achievement of sustainable development, ecological compensation has become an important environmental policies and development strategies of economic, social, economic and environmental development to a certain stage of the inevitable choice.

China's ecological compensation from the initial subsidies for environmental protection against the current value of ecosystem services for water purchase and development restrictions and other aspects of compensation system, concept and content development experience from the natural to the human, ecological construction and management of environmental economic policy process, different scholars of ecological compensation concept and the understanding of what is different (Teddy Wang, 2006; WANG Jinnan, 2005; von Orient, 2006; Hui-Yuan, 2006), one of the important differences is the general sense of pollution treatment and sewage charges are the scope of ecological compensation. WANG Jin-nan ecological compensation made to the concept and content are more widely accepted, WANG Jin-nan that include the four aspects of ecological compensation service, compensation (Payment for Ecological service): the value of ecosystem services to offer to pay. Resources added (Resource based EC): ecological compensation for the sense of natural resources, natural resources, "accounting for compensation"; damage compensation (Damage 1 BasedEc): destruction of personal and corporate environmental behavior and ecological consequences of an economic punishment; the development of compensation (Development BasedEC): to give up on protecting the environment or the behavior of opportunities to be compensated, the compensation the right to development; protection Compensation (ConservatfonBasedEC): of great ecological value of the area or object conservation inputs. The concept of ecological compensation includes the broad and narrow understanding. Broad ecological compensation includes compensation for environmental pollution and ecological function of compensation. Narrow ecological compensation, while others refer to the ecological function or ecological value of the compensation, includes that for the protection and restoration of ecological environment and its functions and to pay the price, sacrifice areas, units and individuals for economic compensation; on the use of land for development, minerals, forests, grasslands, water, wildlife and other natural resources and damage the natural landscape and ecological functions, or result in the loss of ecological value of the units and individuals for financial compensation.

\subsection{East River Basin}

East River Basin water resource protection Ecological compensation mechanism should include the East River basin main water source protection zones of ecological compensation and compensation for repayment of the principal subjects, namely, the power of the main ecological compensation mechanism and obligations of the principal.

Specific to the East River watershed source protection zones, the repayment of principal, including the East River valley area of local government water conservation and water resource protection zone for the East River 
basin have contributed to the ecological environment protection units or individuals.

Taking into account the determination of the main basin of compensation, from the upstream and downstream watershed size and scope, as well as watershed stakeholders, responsibilities and obligations, be considered. Therefore, the East River Basin water resource protection zone of the main ecological compensation includes two aspects: everything from the use of water resources in the East River to benefit the group; all life or the production process emissions of pollutants to the outside world affecting the East River and East River Basin water quality basin unit individual.

As compensation for the implementation and operation of the main eco-compensation mechanism is to determine the essential characteristics of the core content, in accordance with the implementation and operation of the mechanism of the main differences in compensation and the government can be divided into two main types of market compensation:

First, it is the government compensation. Government compensation is based on national or higher levels of government for the implementation and compensation subject to regional governments, etc. to fill Compensation object to regional development goals such as compensation. Among them, mainly it is based on fiscal transfers. Financial transfers Refers to all levels of government that existed between the difference in the basis of financial ability to achieve equality across the public service into a subject and practice A system of financial capital or fiscal balance. Since 1994, implementation of the tax system in China has become the central fiscal transfers balanced Side development and an important way of compensation, such as the 2001 central government revenue and expenditure account for the national fiscal income and expenditure $52.14 \%$ and $30.15 \%$ Huge financial transfers of funds for ecological compensation funds to provide a good foundation, but not into the ecological compensation. The focus for the financial transfer payment is not a part of the current fiscal transfers in China's 10 of the most important factor. Nevertheless, the fiscal transfer Payment is the most direct means of ecological compensation is most easily implemented means. To increase financial transfer payments impact on ecological environment Factor weight, increased focus on ecologically fragile areas and ecological protection support, according to the principle of equality of public services, increase Ecological compensation of fiscal transfers system, the Ministry of Finance's "2003 government budget revenue and expenditure subject" in environmental protection and ecological Care-related expenditure of about 30.

Provincial administrative regions cross river, river upstream source areas of natural forest conservation and farmland Forests and grasslands project has become a national financial key areas of ecological compensation. The result of the central and local governments can protect the ecological environment. The loss of revenues caused by local, national financial transfer payment as funding arrangements for the important factors. East River Basin water resource protection zone present ecological compensation approach is the government compensation, mainly financial subsidies, preferential policies, project implementation for the form of compensation, that is, investment or government-led government financial transfer payment system based, private investment less. June 2005, "East River source region the implementation of ecological compensation mechanism for the program" introduced.

Second, it is market compensation mechanisms. Through market transactions or payments, cash ecology (environment) the value of services, through market transactions, optimize the allocation of resources to achieve watershed market-oriented model. Because of this model, based on clear property rights in the market, based on self-dealing. Water resources, for example, Yiwu, Zhejiang Dongyang learn from Western countries and interstate water trading in the international experience, using market mechanisms to achieve the basin's ecological compensation. After Shaoxing and Cixi have also established trade relations between water resources, through market transactions or payments, cash ecological (environmental) services value.

\subsection{The Analysis on Sanjiangyuan}

Over the past 10 years, China has started the implementation of the returning farmland to forest, pasture, natural forest protection, Beijing and Tianjin sandstorm source control, the southwest karst rocky desertification area of governance, Sanjiangyuan nature reserve in Qinghai, Gansu Gannan important source of water recharge area of the Yellow River such as the nature of ecological compensation has some major ecological construction projects, with a total investment of more than 7000 billion Yuan, of which the nature of the expenditures for a variety of subsidies for the more than 3,000 billion Yuan.

Through the establishment of compensation mechanism is to make the ecological environment of the internalization of external costs, the formation of the ecological environment beneficiaries pay spoilers compensation, builders and protectors of a reasonable compensation for a favorable operating mechanism, thereby enhancing the ecological environment of the community consciousness. Worth looking forward to is that the current parties are speeding up the development of "Eco-Compensation Ordinance," which will make the 
future more in the practical operation "law" Keyi. But overall, China's ecological environment is relatively fragile situation has not fundamentally changed, particularly in promoting the ecological construction and environmental protection interests do not straighten out. "Eleventh Five-year" eco-environmental planning to limit the development of regional and prohibition of the development of regional explicitly provides that: limits the development of regional major national ecological security, including those related to protected areas of natural forest resources, forest area, grassland, "three" areas, an important water source protection areas, serious soil erosion areas and so on; prohibiting the development of region is dominated by various types of nature reserves established by law. The relationship between these regions the supply of the national ecological security and safety of agricultural products, therefore, to establish and improve the ecological environment compensation mechanisms in these areas for the protection of national ecological safety of reasonable compensation for the contribution made by the proper meaning of a question.

In recent days, from the Shizuishan City, held an international seminar ecological compensation mechanism for uploading to the message, our country will be summing up the international and domestic eco-environment compensation mechanism based on the successful experience, accelerate the establishment of ecological compensation mechanism in the framework of policies and regulations.

\subsection{Analysis on Western Region}

In the western region is an important ecological security barrier. Chinese major water sources and water conservation district, soil conservation, and priority areas of desertification, biodiversity, protected areas, mostly in the western region. To ensure that the western region simultaneously with the national comprehensive goal of building a moderately prosperous society requires not only the western region have a choice, to focus on characteristics and advantages of accelerating industrial development, enhance hematopoietic function, but also to accelerate the establishment of a sound ecological compensation mechanism, in particular through increased the central government transfer payments to promote this region while protecting the ecological environment, and continuously improve the urban and rural incomes.

National Development and Reform Commission, Ministry of Environmental Protection responsible person recently said that the establishment of a sound eco-compensation mechanism is a new strategic task, all the work has just started and there is till scope of compensation is not clear, scientific standards of compensation, the compensation model of relatively simple, funding sources, lack of policies and regulations system lag and other issues.

\subsection{Summary of Good Experience on Eco-compensation Issue}

In order to stimulate the eco-compensation mechanism, the government should accelerate the establishment of "Environmental Finance." Environmental finance, as an important component of public finances, increase financial transfer payments in the intensity of ecological compensation. In the central and provincial governments set up special funds for ecological construction included in the fiscal budget, the local governments will also increase the ecological compensation and support for eco-environmental protection. To expand the sources of funds, eco-compensation fund can issue tickets. In accordance with sound ecological compensation mechanism, and further adjust and optimize the structure of financial expenditure. The use of the funds should be focused on the less developed regions, important ecological function areas, water source areas and nature reserves preferentially support the significant role of regional ecological and environmental protection, watershed of key environmental protection projects, increase regional, watershed of pollution prevention and pollution prevention and control of new technologies and new process development and application of funding support. Key support for mine environmental management, and promote ecological restoration and land consolidation mine combined to achieve ecological management of land resources development and a virtuous circle. Taken "to represent the relief" and other measures, through monetary assistance or in-kind subsidies, support development and utilization of biogas, wind, solar and other non-plant renewable fuel energy sources, to ensure the "break-chao also planting" to solve the rural areas, especially the western rural areas fuel to the problem.

\section{Suggestion and Analysis on Eco-compensation System}

According to reports, the next step, the state will reinforce efforts to promote in three areas:

The establishment of ecological compensation mechanism carries out the pilot. The government should continue to do well in Qinghai Three Rivers, south-middle water sources and other central eco-compensation pilot projects, when conditions are ripe and then select a representative inter-provincial river basin, the main mineral resources, important ecological function areas to carry out eco-compensation pilot projects, to start the implementation of Tibet grassland ecological compensation pilot. 
Further expansion of forest ecological benefits compensation coverage to continuously improve the compensation standards. At the same time, encouraging local according to local practice, through financial assistance, targeted assistance, aid support a variety of ways, for ecological function areas as a result strengthen ecological protection of the building to carry out compensation for loss of profits caused by the pilot.

The local government can formulate and improve in line with the concept of ecological compensation system for regional policy. In the central and provincial finance departments to increase transfer payments for ecological protection and restoration expenses. National arrangements for investment in capital construction budget, focusing on the ecological function areas of infrastructure and public service facilities, are supporting suitable for industrial development. To actively study and improve the ecological environment protection and construction in favor of the land policy, population policy, tax policy, and guide commercial banks to capital and social capital, to invest in eco-environmental protection and ecological function areas projects.

Strengthening ecological and environmental compensation mechanism for the system and regulations, Stepping up research to develop "eco-Compensation Ordinance," and specifically the implementation of ecological compensation and other remedies to further refine watershed, forests, grasslands, wetlands, mineral resources and other areas of the implementation details are the major measurements for the government.

(1) Strengthening the awareness of resources and environmental rights, the establishment of effective evaluation mechanisms.

To State environmental property rights, and to explore the ecological property rights based on eco-compensation mechanism, Ming Ensure compensation of the main, scientific definition of compensation, the effective protection of the ecological environment; reference to international Experience, the establishment of a community-oriented ecological compensation system for monitoring and evaluation institutions, or participating.

The government should set the pattern according to the state system to establish a regional management of ecological compensation mechanism for ecological compensation Progress in the implementation of construction projects, technical guidance, maintenance control.

(2) To enhance ecological compensation special legislation, improve the financing system. Clear ecological complement Compensation of the main responsibilities and obligations, improve the legal system, timely amendments to the Environmental Protection of a single law, Development of specialized "eco-compensation law", to achieve a sound ecological compensation mechanism of the network; Set up a special development fund, use of environmental financing policies get through the "bottleneck", the full benefit With financial, credit, securities finance market in three ways to promote the building of the establishment of government support Pay based, supplemented by other social forces to compensate the working mechanism, and strengthen market Compensation institution.

(3) To strengthen the integrated management of ecological compensation, compensation to achieve diversification. Advance National, local, regional, industry, coordinated multi-level government executives, market operation, Diversified business model of public participation in development; encouraging environment among stakeholders achieved through voluntary negotiation for the region, the project's financial vertical compensation, region horizontal compensation, market compensation for the three models in one of the ecological compensation, to achieve funding, technology Surgery, physical, policy, intellectual combination of the form of compensation..

(4) Establishment of environmental finance system, improving the compensation policy for resources and the environment. In the perfectly, it is based on the current environmental tax policy, the environment into the current public, financial system to the compensation fund lottery environment, ecological compensation tax, the introduction of foreign countries. Gold projects in the form of increasing the financial transfer payments to the intensity of ecological compensation, and should be regulated Fan use and management of its collection, collected by the financial department of the rational allocation, complete compensation policy of good resources and environment.

\section{Conclusion}

Ecological compensation mechanism based on the protection of ecological environment and promoting harmony between man and nature for the purpose, according to the value of ecosystem services, ecological protection costs, the development of opportunity cost, integrated use of administrative and market measures, environmental protection and construction-related adjustment of interests between the parties the relationship between environmental and economic policy. Mainly for the regional ecological protection and pollution prevention in the field, and is an economic incentive, and the "polluter pays" principle co-exist, based on the "beneficiaries pay and destroyer pays" principle of environmental economic policies. 
The establishment of ecological compensation mechanism to implement the scientific concept of development an important measure will help promote environmental protection mainly by administrative means to achieve from the comprehensive use of legal, economic, technical and administrative means to shift resources to help promote the sustainable use of speed up the construction of environment-friendly society, to achieve different regions, the harmonious development of different interest groups.

The establishment of ecological compensation mechanism is to implement the urgent task of the new period requirements of environmental protection, the State Council on the establishment of ecological compensation mechanism put forward specific demands, and as an important part of strengthening environmental protection. "The State Council on Implementing the Scientific Concept of Development and Strengthening Environmental Protection" requirements: "To improve the ecological compensation policy, the establishment of ecological compensation mechanism as soon as possible. Central and local fiscal transfers should take into account ecological compensation factors, national and local pilot ecological compensation can be carried out, respectively. "State" comprehensive energy conservation program of work "explicitly requested resource development to improve and perfect the mechanism of ecological compensation and carry out inter-basin pilot ecological compensation.

The actual situation from the starting conditions and environmental protection, ecological compensation mechanism in China at present the focus areas of four areas, namely:

(1) Nature of ecological compensation. To improve and broaden the investment channels for nature reserves, improve and standardize the level of nature reserves; guide protected areas and surrounding community residents produce lifestyle changes to reduce the pressure on nature reserves around the community; a comprehensive evaluation of various construction projects around the natural Ecology and environmental damage or functional zoning adjustment, adjust the scope of the ecological damage, study the establishment of ecological compensation system for nature reserves.

(2) Important ecological function of the ecological compensation. Promote the establishment of important ecological function areas and improve the coordination of management and investment mechanisms; establishment and improvement of important ecological function of the ecological environment quality monitoring and evaluation system, an important ecological function in the region to increase urban and rural environment comprehensive efforts; to carry out important ecological functions of ecological Accounting of compensation, the establishment of important ecological functions of the ecological compensation system.

(3) Ecological compensation of mineral resources development is full implementation of the mining environmental management and ecological restoration of responsibility. The joint development of relevant scientific assessment of mineral resources and environmental management and mine restoration deposit compensation fund for the use of ecological conditions, study and formulate a scientific development of mineral resources of ecological compensation system.

(4) Watershed Protection of ecological compensation should ensure that the water quality around the world to achieve the goal, according to immigration status to determine the water quality standards for lateral compensation; structures contribute to the establishment of ecological compensation mechanism of the government management platform, facilitating the establishment of mechanisms for building and sharing of ecological protection; to strengthen coordination with the parties concerned, promoting the development of water and various administrative special fund for environmental protection.

\section{References}

Bator FM. (1958). The anatomy of market failure, Journal of Environmental Management, (3).

Bird PJ. (1987). The transferability and depletability of externalities, Trans.Inst.Br. Geogr., (11).

Daily GC. (1997). Nature's services: societal dependence on natural ecosystems.

Head JG. (1962). Public goods and public policy.

Pigou AC. (1971). The economics of welfare.

Rosa H,Kandel S.Dimas L. (2003). Compensation for environmental services and rural communities: lessoas from the Americas and key issues for strengthening community strategies.

Scherr S, white A.Khare A. (2004). For services rendered:the current status and future potential of markets for the ecosystem services provided by tropical forests.

Wander S. Vargas MT. (2005). Beyond"market":why terminology matters.

Wunder S. (2005). Payments for environmental services:some nuts and bolts. 